\title{
Measuring Journal Linking Success from a Discovery Service
}

\author{
Kenyon Stuart, \\ Ken Varnum, and \\ Judith Ahronheim
}

\begin{abstract}
Online linking to full text via third-party link-resolution services, such as Serials Solutions 360 Link or Ex Libris' SFX, has become a popular method of access to users in academic libraries. This article describes several attempts made over the course of the past three years at the University of Michigan to gather data on linkage failure: the method used, the limiting factors, the changes made in methods, an analysis of the data collected, and a report of steps taken locally because of the studies. It is hoped that the experiences at one institution may be applicable more broadly and, perhaps, produce a stronger data-driven effort at improving linking services.
\end{abstract}

\section{INTRODUCTION}

Online linking via vended services has become a popular method of access to full text for users in academic libraries. But not all user transactions result in access to the desired full text.

Maintaining information that allows the user to reach full text is a shared responsibility among assorted vendors, publishers, aggregators, local catalogers, and electronic access specialists. The collection of information used in getting to full text can be thought of as a supply chain. To maintain this chain, libraries need to enhance the basic information about the contents of each vendor package-a collection of journals bundled for sale to libraries - with added details about local licenses and holdings. These added details need to be maintained over time. Since links, platforms, contracts, and subscriptions change frequently, this can be a time-consuming process. When links are unsuccessfully constructed within each system, considerable troubleshooting of a very complex process is required to determine where the problem lies. Because so much of the transaction is invisible to the user, linking services have come to be taken for granted by the community, and performance expectations are very high. Failure to reach full text reflects poorly on the institutions that offer the links, so there is considerable interest for and value to the institution in improving performance.

Kenyon Stuart (kstuart@umich.edu) is Senior Information Resources Specialist, Ken Varnum (kvarnum@umich.edu) is Web Systems Manager, and Judith Ahronheim (jaheim@umich.edu) is Head, Electronic Resource Access Unit, University of Michigan Library, Ann Arbor, Michigan. 
Improving the success rate for users can best be achieved by acquiring a solid understanding of the nature and frequency of problems that inhibit full-text retrieval. While anecdotal data and handling of individual complaints can provide incremental improvement, larger improvement resulting from systematic changes requires more substantial data, data that characterizes the extent of linking failure and the categories of situations that inhibit it.

\section{LITERATURE REVIEW}

OpenURL link resolvers are "tool[s] that helps library users connect to their institutions' electronic resources. The data that drives such a tool is stored in a knowledge base." Since the codification of the OpenURL as an ANSI/NISO standard in 2004, ${ }^{2}$ OpenURL has become, in a sense, the glue that holds the infrastructure of traditional library research together, connecting citations and full text. It is well recognized that link resolution is an imperfect science. Understanding what and how OpenURLs fail is a time-consuming and labor-intensive process, typically conducted through analysis of log files recording attempts by users to access a full-text item via OpenURL.

Research has been conducted from the perspective of OpenURL providers, showing which metadata elements encoded in an OpenURL were most common and most significant in leading to an appropriate full-text version of the article being cited. In 2010, Chandler, Wiley, and LeBlanc reported on a systematic approach they devised, as part of a Mellon grant, to review the outbound OpenURLs from L'Année Philologique. ${ }^{3}$ They began with an analysis of the metadata elements included in each OpenURL and compared this to the standard. They found that elements critical to the delivery of a full-text item, such as the article's starting page, were never included in the OpenURLs generated by L'Année Philologique. ${ }^{4}$ Their work led to the creation of the Improving OpenURLs Through Analytics (IOTA) working group within the National Information Standards Organization (NISO).

IOTA, in turn, was focused on improving OpenURL link quality at the provider end. "The quality of the data in the link resolver knowledge base itself is outside the scope of IOTA; this is being addressed through the NISO KBART initiative."5,6 Where IOTA provided tools to content providers for improving their outbound OpenURLs, KBART provided tools to knowledge base and linking tool providers for improving their data. Pesch, in a study to validate the IOTA process, discovered that well-formed OpenURLs were generally successful, however:

The quality of the OpenURL links is just part of the equation. Setting the proper expectations for end users also need to be taken into consideration. Librarians can help by educating their users about what is expected behavior for a link resolver and end user frustrations can also be reduced if librarians take advantage of the features most content providers offer to control when OpenURL links display and what the links say. Where possible the link text should indicate to the user what they will get when they click it. ${ }^{7}$ 
Missing from the standards-based work described above is the role of the OpenURL middleman, the library. Price and Trainor describe a method for reviewing OpenURL data and identifying the root causes of failures. ${ }^{8}$ Through testing of actual OpenURLs in each of their systems, they arrived at a series of steps that could be taken by other libraries to proactively raise OpenURL resolution success rates. Several specific recommendations include "optimize top 100 most requested journals" and "optimize top ten full text target providers." 9 That is, make sure that OpenURLs leading to content from the most frequently used journals and content sources are tested and are functioning correctly. Chen describes a similar analysis of broken link reports derived from Bradley University library's SFX implementation over four years, with a summary of the common reasons links failed. ${ }^{10}$ Similarly, O'Neill conducted a small usability study whose recommendations included providing "a system of support accessible from the page where users experience difficulty,"11 although her recommendations focused on inline, context-appropriate help rather than error-reporting mechanisms.

Not found in the literature are several systematic approaches that a library can take to proactively collect problem reports and manage the knowledge base accordingly.

\section{METHOD}

We have taken a two-pronged approach to improving link resolution quality, each relying on a different kind of input. The first uses problem reports submitted by users of our Summon ${ }^{\mathrm{TM}}$ powered article discovery tool, ArticlesPlus. ${ }^{12}$ The second focuses on the most commonly-accessed full-text titles in our environment, based on reports from 360 Link. We have developed this dual approach in the expectation that we will catch more problems on lesser-used full-text sources through the first approach, and problems whose resolution will benefit the most individuals through the second.

\section{User Reports}

The University of Michigan Library uses Summon as the primary article discovery tool. When a user completes a search and clicks the "MGet It" button (see figure 1)—MGet It is our local brand for the entire full-text delivery process - the user is directed to the actual document through one of two mechanisms:

1. Access to the full-text article through a Summon Index-Enhanced Direct Link. (Some of Summon's full-text content providers contribute a URL to Summon for direct access to the full text. This is known as an Index-Enhanced Direct Linking [Direct Linking].)

2. Access to the full text article through the University Library's link resolver, 360 Link. At this point, one of two things can happen:

a. The University Library has configured a number of full-text sources as "direct to full text" links. When a citation leads to one of these sources, the user is directed to the article (or as close to it as the content provider's site allows (sometimes to an issue 
table of contents, sometimes to a list of items in the appropriate volume, and-rarely in this instance-— to the journal's front page; the last outcome is rare in our environment because the University Library prefers full-text links that get closer to the article and has configured 360 Link for that outcome).

b. For those full-text sources that do not have direct-to-article links, 360 Link is configured to provide a range of possible delivery mechanisms, including journal-, volume- or issue-level entry points, document-delivery options (for cases where the library does not license any full-text online sources), the library catalog (for identifying print holdings for a journal), and so on.

From the user perspective, mechanisms 1 and 2a are essentially identical. In both cases, a click on the MGet It icon takes the user to the full text in a new browser window. If the link does not lead to the correct article for any reason, there is no way in the new window for the library to collect that information. Users may consider item $2 \mathrm{~b}$ results as a failure because the article is not immediately perceptible, even if the article is actually available in full text after two or more subsequent clicks. Because of this user perception, we interpreted 2 b results as "failures."

\begin{tabular}{|c|c|c|}
\hline Save to & $\begin{array}{l}\text { The Future of OpenURL Linking } \\
\text { by Jason S Price, Cindi Trainor } \\
\text { Library Technology Reports Vol. 46, Issue 7. Date: Oct } 2010 \text { Start } \\
\text { Page: } 27 . \\
\text { Format: Book Review } \\
\text { "...Previous chapters in this report have addressed the continuing } \\
\text { importance of OpenURL linking in libraries and presented interface- } \\
\text { based and data-based ways to improve local OpenURL link resolver } \\
\text { systems..." more... }\end{array}$ & $\begin{array}{l}\text { EGet It } \\
\text { Full Text Online } \\
\text { Full text link not working? } \\
\text { Please let us know. }\end{array}$ \\
\hline
\end{tabular}

Figure 1. Sample Citation from ArticlesPlus

In an attempt to understand this type of problem, following the advice given by O'Neill and Chen, we provide a problem-reporting link in the ArticlesPlus search-results interface each time the fulltext icon appears (see the right side of figure 1). When the user clicks this problem-reporting link, they are taken to a Qualtrics survey form that asks for several basic pieces of information from the user but also captures the citation information for the article the user was trying to reach (see figure 2). 
Note: Most articles included in ArticlesPlus are available only to members of the University of Michigan community

Please describe the problem you experienced when you clicked the "MGet It" icon to get the full text.

There was no article

I got the wrong article

I I nded up at a page on the journal's web site, but not the article

I was asked to log in to the publisher's site

Something else happened (please explain):

(2)

Additional comments about this problem (optional)

Your email address:

Figure 2. Survey Questionnaire for Reporting Linking Problems

This survey instrument asks the user to characterize the type of delivery failure with one of four common problems, along with an "other" text field:

- There was no article

- I got the wrong article

- I ended up at a page on the journal's web site, but not the article

- I was asked to log in to the publisher's site

- Something else happened (please explain):

The form also asks for any additional comments and requires that the user provide an email address so that library staff can contact the user with a resolution (often including a functioning full-text link) or to ask for more information.

In addition to the information requested from the user, hidden fields on this form capture the Summon record ID for the article, the IP address of the user's computer (to help us identify if the problem could be a related to our EZProxy configuration), a time and date stamp of the report's submission, and the brand and version of web browser being used. 
The results of the form are sent by email to the University Library's Ask a Librarian service, the library's online reference desk. Ask a Librarian staff make sure that the problem is not associated with the individual user's account (that they are entitled to get full text, that they were accessing the item from on campus or via the proxy server or VPN, etc.). When user-centric problems are ruled out, the problem is passed on to the library's Electronic Access Unit in Technical Services for further analysis and resolution.

\section{Random Sampling}

User-reported problems are only one picture of issues in the linking process. We were concerned that user reports might not be the complete story. We wanted to ensure that our samples represented the full range of patron experiences, not just that of the ones who reported. So, to get a different perspective, we instituted a series of random sample testing using logs of document requests from the link resolver, 360 Link.

\section{Linking Review}

Our first large-scale review of linking from ArticlesPlus was conducted in 2011. This first approach was based on a log of the Summon records that had appeared in patron searches and for which our link resolver link had been clicked. For this test we chose a slice of the log covering the period from January 30-February 12, 2011. This period was chosen because it was well into the academic term and before Spring Break, so it would provide a representative sample of the searches people had performed. The resulting slice contained 13,161 records. For each record the log contained the Summon ID of the record. We used this to remove duplicate records from the log to ensure we were not testing linking for the same record more than once, leaving us with a spreadsheet of 10,497 records, one record per row. From the remaining records we chose a sample of 685 records using a random number generator tool, Research Randomizer (http://www.randomizer.org/form.htm), to produce a random, nonduplicating list of 685 numbers with values from 1 to 10,497 . Each of the 685 numbers produced was matched to the corresponding row in the spreadsheet starting with the first record listed in the spreadsheet. For each record we collected the data in figure 3. 
1. The Summon ID of the record

2. The raw OpenURL provided with the record.

3. A version of the OpenURL that may have been locally edited to put dates in a standard format.

4. The final URL provided to the user for linking to the resource. This would usually be the OpenURL from \#3 containing the metadata used by the link resolver to build its full-text links. Currently it is an intermediary URL provided by the Summon API. This URL may lead to an OpenURL or to a Direct Link to the resource in the Summon record.

5. The classification of the link in the Summon record. This was either "Full Text Online" or "Citation-Only."

6. The date the link resolver link was clicked.

7. The page in the Summon search results the link resolver link was found.

8. The position within the page of search results where the link resolver link was located.

9. The search query that produced the search results.

Figure 3. Data Points Collected

The results from this review were somewhat disappointing, with only $69.5 \%$ of the citations tested leading directly to full text. At the time Direct Linking did not yet exist, so "direct to full text" linking was only available through the 1-Click feature of 360 Link. The 1-Click feature attempts to lead patrons directly to the full text of a resource without first going through the 360 Link menu. 1-Click was used for 579 or $84.5 \%$ of the citations tested with $15.3 \%$ leading to the 360 Link menu. Of the citations that used 1-Click, 476 or $82.2 \%$ led directly to full text, so when 1-Click was used it was rather successful. Links for about $30.5 \%$ of the citations led either to a failed attempt to reach full text through 1-Click or directly to the 360 Link menu. The 2011 review included looking at the full-text links that 360 Link indicated should lead directly to the full text as opposed to the journal, volume or issue level. When we reviewed all of the "direct to full text" links generated by 360 Link, not only the ones used by 1-Click, we found a variety of reasons why those links did not succeed in leading to the full text. The top five reasons found for linking failures are the following:

1. incomplete target collection

2. incorrect syntax in the article/chapter link generated by $360 \mathrm{Link}$

3. incorrect metadata in the Summon OpenURL

4. article not individually indexed

5. target error in targeturl translation 
Collectively, these reasons were associated with the failure of $71.5 \%$ of the "direct to full text" links. As we will show later, these problems were also noted in our most recent review of linking quality.

\section{Move to Quarterly Testing}

After this review in 2011, we decided to perform quarterly testing of the linking so we would have current data on the quality of linking. This would give us information on the effectiveness of any changes we and ProQuest had made independently to improve the linking. We could see where linking problems found in previous testing had been resolved and where new ones might exist.

However, we needed to change how we created our sample. While the data gathered in 2011 provided much insight into the workings of 360 Link, testing the 685 records produced 2,210 fulltext links. Gathering the data for such a large number of links required two months of part-time effort by two staff members as well as an additional month of part-time effort by one staff member for analysis. This would not be workable for quarterly testing. As an alternative we decided to test two records from each of the 100 serials most accessed through the link resolver. This gave us a sample we could test and analyze within a quarter based on serials that our patrons were using. We felt that we could gather data for such a sample within three to four weeks instead of two months. The list was generated using the "Click-Through Statistics by Title and ISSN (Journal Title)" usage report generated through the ProQuest Client Center administration GUI. We searched for each serial title within Summon using the serial's ISSN or the serial's title when the ISSN was not available.

We ordered the results by date, with the newest records first. We wanted an article within the first two to three pages of results so we would have a recent article, but not one so new it was not yet available through the resources that provide access to the serial. Then we reordered the results to show the oldest records first and chose an article from the first or second page of results. Our goal was to choose an article at random from the second or third page while ignoring the actual content of the article so as not to introduce a selection bias by publisher or journal. Another area where our sample was not truly random involved supplement issues of journals. One problem we found with the samples collected was that they contained few items from supplemental issues of journals. Linking to articles in supplements is particularly difficult because of the different ways supplement information is represented among different databases. To attempt to capture linking information in this case we added records for articles in supplemental issues. Those records were chosen from journals found in earlier testing to contain supplemental issues. We searched Summon for articles within those supplemental issues and selected one or two to add to our sample.

One notable thing is the introduction of Direct Linking in our Summon implementation between the reviews for the first and second quarters of 2012. ProQuest developed Direct Linking to 
improve linking to resources (including but not limited to full text of articles) through Summon. Instead of using an OpenURL which must be sent to a link resolver, Direct Linking uses information received from the providers of the records in Summon to create links directly to resources through those providers. Ideally, since these links use information from those providers, Direct Linking would not have the problems found with OpenURL linking through a link resolver such as 360 Link. Not all links from Summon use Direct Linking, and as a result we had to take into account the possibility that any link we clicked could use either OpenURL linking or Direct Linking.

\section{Current Review: Back to Random Sampling}

While the above sampling method resulted in useful data, we also found it had some limitations. When we performed the review for the second quarter of 2012, we found a significant increase in the effectiveness of 360 Link since the first quarter 2012 review. This is further described in the findings section of this article. We were able to trace some of this improvement to changes ProQuest had made to 360 Link and to the OpenURLs produced from Summon. However, we were unable to fully trace the cause of the improvement and were unable to determine if this was real improvement that would be persistent. To resolve these problems, we have returned to using a random sample in our latest review, but with a change in methods.

\section{Current Review: Determining the Sample Size}

We wanted to perform a review that would be statistically relevant and could help us determine if any changes in linking quality were persistent and not just a one-time event. Instead of testing a single sample each quarter we decided to test a sample each month over a period of months. One concern with this was the sample size, as we wanted a sample that would be statistically valid but not so large we could not test it within a single month. We determined that a sample size of 300 would be sufficient to determine if any month-to-month changes represent a real change. However, in previous testing we had learned that because of re-indexing of the Summon records, Summon IDs that were valid when a patron performed a search might no longer be valid by the time of our testing. We wanted a sample of 300 still-valid records, so we selected a random sample larger than that amount. So, we decided to test 600 records each month to determine if the Summon IDs were still valid.

\section{Current Review: Methods}

When generating each month's sample we used the same method as in 2011. We asked our Web Systems group for the logs of full-text requests from the library's Summon interface for the period of November 2012-February $2013 .{ }^{13}$ We processed each month's $\log$ file within two months of the user interactions. To generate the 600-record sample, after removing records with duplicate Summon IDs, we used a random number generator tool, Research Randomizer, to produce a random, nonduplicating list of 600 numbers with values from 1 to the number of unique records. Each of the 600 numbers produced was matched to the corresponding row in the spreadsheet of 
records with unique Summon IDs. Once the 600 records were tested and we had a subset with valid Summon IDs, we generated a list of 300 random, nonduplicating numbers with values from 1 to the number of records with valid Summon IDs. Each of the 300 numbers produced was matched to the corresponding row in a spreadsheet of the subset of records with valid Summon IDs. This gave us the 300-record sample for analysis.

Testing was performed by two people, a permanent staff member and a student hired to assist with the testing. The staff member was already familiar with the data gathering and recording procedure and trained the student on this procedure. The student was introduced to the library's Summon implementation and shown how to recognize and understand the different possible linking types: Summon Direct Linking, 360 Link using 1-Click, and 360 Link leading to the 360 Link menu. Once this background was provided, the student was introduced to the procedure for gathering and recording data. The student was given suggestions on how to find the article on the target site if the link did not lead directly to the article and how to perform some basic analysis to determine why the link did not function as expected. The permanent staff member reviewed the analysis of the links that did not lead to full text and applied a code to describe the reason for the failure.

Based on our 2011 testing, we expected to see one of two general results in the current round.

1. 360 Link would attempt to connect directly to the article because of our activating the 1Click feature of 360 Link when we implemented the link resolver. With 1-Click, 360 Link attempts to lead patrons directly to the full text of a resource without first having to go through the link resolver menu. Even with 1-Click active we provide patrons a link leading to the full 360 Link menu, which may have other options for leading to the full text as well as links to search for the journal or book in our catalog.

2. The other possible result was the link from Summon leading directly to the 360 Link menu.

Once Direct Linking was implemented after we began this round, a third result became possible (a direct link from Summon to the full text).

For each record we collected the data shown in figure 4. 
1. Date the link from Summon record was tested.

2. The URL of the Summon record.

3. *The OpenURL generated by clicking the link from Summon. This was the URL in the address bar of the page to which the link led. This is not available when Direct Linking is used.

4. The ISSN of the serial or ISBN of the book.

5. The DOI of the article/book chapter if it was available.

6. The citation for the article as shown in the 360 Link menu or in the Summon record if Direct Linking was used.

7. *Each package (collection of journals bundled together in the knowledgebase) for which 360 Link produced an electronic link for that citation.

8. *The order in the list of electronic resources in which the package in \#7 appeared in the 360 Link menu.

9. *The Linking Level assigned to the link by 360 Link. This level indicates how close to the article the link should lead the patron, with article-level or chapter-level links ideally taking the patron directly to the article/book chapter. The linking levels recorded in our testing starting with the closest to full text were article/book chapter, issue, volume, journal/book and database.

10. *For article-level links, the URL that 360 Link used to attempt to connect to the article.

11. For all full-text links in the 360 Link menu, the URL to which the links led. This was the link displayed in the browser address bar.

12. A code assigned to that link describing the results.

13. A note indicating if full text was available on the site to which the link led. This was only an indicator of whether or not full text could be accessed on that site not an indicator of the success of 1-Click/Direct Linking or the article-level link.

14. A note if this was the link used by 1-Click.

15. A note if Direct Linking was used.

16. A note if the link was for a citation where 1-Click was not used and clicking the link in Summon led directly to the 360 Link menu.

17. Notes providing more detail for the results described by \#12. This included error messages, search strings shown on the target site, and any unusual behavior. The notes also included conclusions reached regarding the cause(s) of any problems.

* Collected only if the link resolver was used.

Figure 4. Data Collected from Sample 
Each link was categorized based on whether it led to the full text. Then the links that failed were further categorized on the basis of the reason for failure (see figure 5 for failure categories).

1. Incorrect metadata in the Summon OpenURL.

2. Incomplete metadata in the Summon OpenURL.

3. Difference in the metadata between Summon and the target. In this case we were unable to determine which site had the correct metadata.

4. Inaccurate data in the knowledgebase. This includes incorrect URL and incorrect ISSN/ISBN.

5. Incorrect coverage in the knowledgebase.

6. Link resolver insufficiency. The link resolver has not been configured to provide deep linking. This may be something that we could configure or something that would require changes in 360 Link.

7. Incorrect syntax in the article/chapter link generated by 360 Link.

8. Target site does not appear to support linking to article/chapter level.

9. Article not individually indexed. This often happens with conference abstracts and book reviews which are combined in a single section.

10. Translation error of the "targeturl" by target site.

11. Incomplete target collection. Site is missing full text for items that should be available on the site.

12. Incorrect metadata on the target site.

13. Citation-Only record in Summon. Summon indicates only the citation is available so access to full text is not expected.

14. Error indicating cookie could not be downloaded from target site. This sometimes happened with 1-Click but the same link would work from the 360 Link menu.

15. Item does not appear to have a DOI. The 360 Link menu may provide an option to search for the DOI. Sometimes these searches fail and we are unable to find a DOI for the item.

16. Miscellaneous. Results that do not fall into the other categories. Generally used for links in packages for which 360 Link only provides journal/book-level linking such as Directory of Open Access Journals (DOAJ).

17. Unknown. The link failed with no identifiable cause.

Figure 5. List of Failure Categories Assigned 


\section{User-Reported Problems}

In March 2012, we began recording the number of full-text clicks in ArticlesPlus search results (using Google Analytics events). For each month, we calculated the number of problems reported per 1,000 searches and per 1,000 full-text clicks. Graphed over time, the number of problem reports in both categories shows an overall decline. See figures 6 and 7.

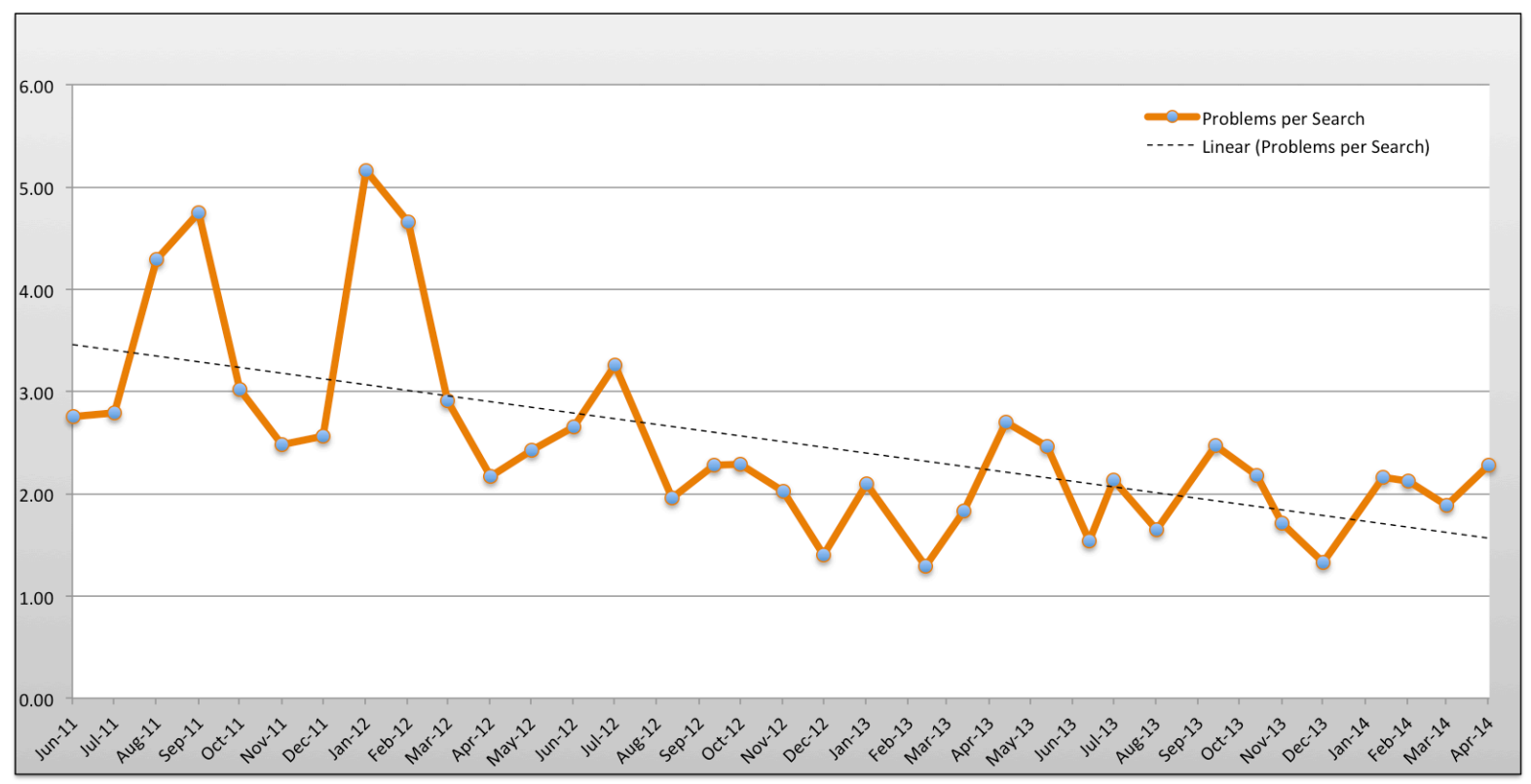

Figure 6. Problems Reported per 1,000 ArticlesPlus Searches (June 2011-April 2014)

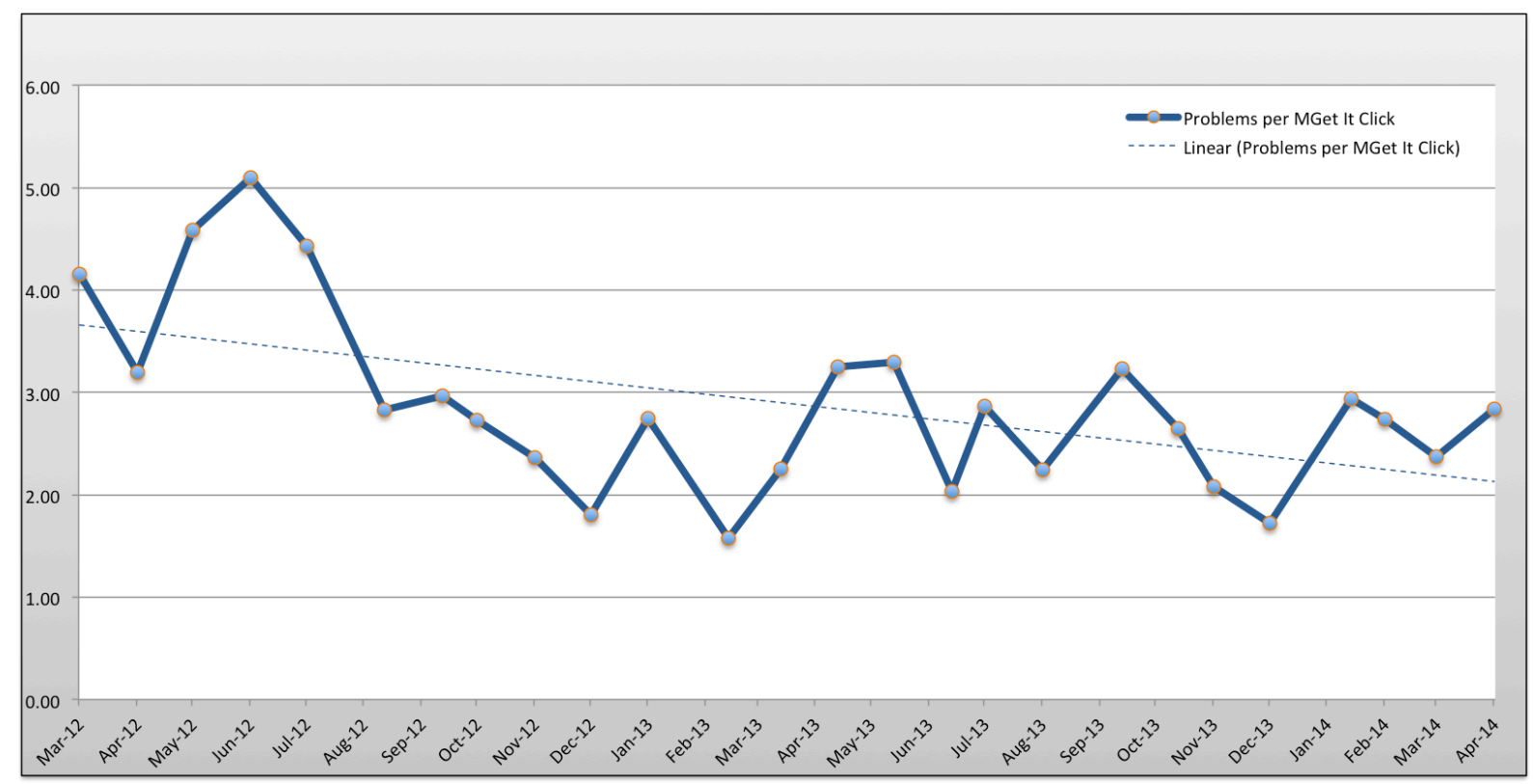

Figure 7. Problems Reported per 1,000 ArticlesPlus Full-Text Clicks (March 2012-April 2014) 
Our active work to update the Summon and 360 Link knowledge bases began in June 2011. The change to Summon Direct Linking happened on February 27, 2012, at a time when we were particularly dissatisfied with the volume of problems reported. We felt the poor quality of OpenURL resolution was a strong argument in favor of activating Summon Direct Linking. We believe this change led to a noticeable improvement in the number of problems reported per 1,000 searches (see figure 6). We do not have data for clicks on the full-text links in our ArticlesPlus interface prior to March 2012, but do know that reports per 1,000 full-text clicks have been on the decline as well (see figure 7).

\section{FINDINGS}

\section{Summary of Random-Sample Testing of Link Success}

In early 2013 we tested linking from ArticlesPlus to gather data on the effectiveness of the linking and to attempt to determine if there were any month-to-month changes in the effectiveness that could indicate persistent changes in linking quality. In this section we will review the data collected from the four samples used in this testing. We will discuss the different paths to full text, Direct Linking vs. OpenURL linking through 360 Link, and their relative effectiveness. We will also discuss the reasons we found for links to not lead to full text.

\section{Paths to Full-Text Access}

As shown below (see table 1) most of the records tested in Summon used Direct Linking to attempt to reach the full text. The percentage varied with each sample tested but they ranged from $61 \%$ to $70 \%$. The remaining records used 360 Link to attempt to reach the full text. Most of the time when 360 Link was used, 1-Click was also used to reach the full text. Between Direct Linking and 1 -Click about $93 \%$ to $94 \%$ of the time an attempt was made to lead users directly to the full text of the article without first going through the 360 Link menu.

\begin{tabular}{|l|l|l|l|l|l|l|l|l|}
\hline & \multicolumn{2}{|l|}{$\begin{array}{l}\text { Sample 1 } \\
\text { November 2012 }\end{array}$} & \multicolumn{2}{l|}{$\begin{array}{l}\text { Sample 2 } \\
\text { December 2012 }\end{array}$} & \multicolumn{2}{l|}{$\begin{array}{l}\text { Sample 3 } \\
\text { January 2013 }\end{array}$} & \multicolumn{2}{l|}{$\begin{array}{l}\text { Sample 4 } \\
\text { January 2013 }\end{array}$} \\
\hline Direct Linking & 205 & $68.3 \%$ & 210 & $70.0 \%$ & 184 & $61.3 \%$ & 190 & $63.3 \%$ \\
\hline 360 Link/1-Click & 77 & $25.7 \%$ & 70 & $23.3 \%$ & 98 & $32.7 \%$ & 87 & $29.0 \%$ \\
\hline 360 Link/360 Link Menu & 18 & $6.0 \%$ & 20 & $6.7 \%$ & 18 & $6.0 \%$ & 23 & $7.7 \%$ \\
\hline Total & 300 & & 300 & & 300 & & 300 & \\
\hline
\end{tabular}

Table 1. Type of Linking 
Attempts to reach the full text through Direct Linking and 1-Click were rather successful. In the testing, we were able to reach full text through those methods from $79 \%$ to about $84 \%$ of the time (see table 2). The remaining cases were situations where Direct Linking/1-Click did not lead directly to the full text or we reached the 360 Link menu.

\begin{tabular}{|l|l|l|l|l|l|l|l|l|}
\hline & \multicolumn{2}{|l|}{$\begin{array}{l}\text { Sample 1 } \\
\text { November 2012 }\end{array}$} & \multicolumn{2}{l|}{\begin{tabular}{l}
\multicolumn{2}{l|}{ Sample 2 } \\
December 2012
\end{tabular}} & \multicolumn{2}{l|}{$\begin{array}{l}\text { Sample 3 } \\
\text { January 2013 }\end{array}$} & \multicolumn{2}{l|}{$\begin{array}{l}\text { Sample 4 } \\
\text { January 2013 }\end{array}$} \\
\hline Direct Linking & 197 & $65.7 \%$ & 204 & $68.0 \%$ & 173 & $57.7 \%$ & 185 & $61.7 \%$ \\
\hline 360 Link/1-Click & 45 & $15.0 \%$ & 47 & $15.7 \%$ & 64 & $21.3 \%$ & 55 & $18.3 \%$ \\
\hline Total out of 300 & 242 & $80.7 \%$ & 251 & $83.7 \%$ & 237 & $79.0 \%$ & 240 & $80.0 \%$ \\
\hline
\end{tabular}

Table 2. Percentage of Citations Leading Directly to Full Text

Table 3 contains the same data but adjusted to remove results that Summon correctly indicated were citation-only. Instead of calculating the percentages based on the full 300 citation samples, they are calculated based on the sample minus the citation-only records. The last row shows the number of records excluded from the full samples.

\begin{tabular}{|c|c|c|c|c|c|c|c|c|}
\hline \multirow[b]{2}{*}{ Direct Linking } & \multicolumn{2}{|c|}{$\begin{array}{l}\text { Sample } 1 \\
\text { November } 2012\end{array}$} & \multicolumn{2}{|c|}{$\begin{array}{l}\text { Sample } 2 \\
\text { December } 2012\end{array}$} & \multicolumn{2}{|c|}{$\begin{array}{l}\text { Sample } 3 \\
\text { January } 2013\end{array}$} & \multicolumn{2}{|c|}{$\begin{array}{l}\text { Sample } 4 \\
\text { January } 2013\end{array}$} \\
\hline & 197 & $65.9 \%$ & 204 & $69.2 \%$ & 173 & $59.0 \%$ & 185 & $62.5 \%$ \\
\hline 360 Link/1-Click & 45 & $15.1 \%$ & 47 & $15.9 \%$ & 64 & $21.8 \%$ & 55 & $18.6 \%$ \\
\hline Total & 242 & $80.9 \%$ & 251 & $85.1 \%$ & 237 & $80.9 \%$ & 240 & $81.1 \%$ \\
\hline Records excluded & 1 & & 5 & & 7 & & 4 & \\
\hline
\end{tabular}

Table 3. Percentage of Citations Leading Directly to Full Text, Excluding Citation-Only Results

\section{Link Failures with Summon Direct Linking and 360 Link 1-Click}

The next two tables show the results of linking for records that used Direct Linking and the citations that used 1-Click through 360 Link. Records that used Direct Linking were more likely to lead testers to full text than 360 Link with 1-Click. For the four samples, Direct Linking led to full text more than $90 \%$ of the time while 1-Click led to full text from about $58 \%$ to about $67 \%$ of the time.

For those records using Direct Linking where Direct Linking did not lead directly to the text, the result was usually a page that did not have a link to full text (see table 4). 


\begin{tabular}{|c|c|c|c|c|c|c|c|c|}
\hline \multirow[b]{2}{*}{ Full Text/Page with full-text link } & \multicolumn{2}{|c|}{$\begin{array}{l}\text { Sample } 1 \\
\text { Nov. } 2012 \\
n=205\end{array}$} & \multicolumn{2}{|c|}{$\begin{array}{l}\text { Sample } 2 \\
\text { Dec. } 2012 \\
n=210\end{array}$} & \multicolumn{2}{|c|}{$\begin{array}{l}\text { Sample } 3 \\
\text { Jan. } 2013 \\
n=184\end{array}$} & \multicolumn{2}{|c|}{$\begin{array}{l}\text { Sample } 4 \\
\text { Jan. } 2013 \\
n=190\end{array}$} \\
\hline & 197 & $96.1 \%$ & 204 & $97.1 \%$ & 173 & $94.0 \%$ & 185 & $97.4 \%$ \\
\hline Abstract/Citation Only & 6 & $2.9 \%$ & 5 & $2.4 \%$ & 6 & $3.3 \%$ & 5 & $2.6 \%$ \\
\hline $\begin{array}{l}\text { Unable to access full text through } \\
\text { available full-text link }\end{array}$ & 1 & $0.5 \%$ & 1 & $0.5 \%$ & 3 & $1.6 \%$ & 0 & $0.0 \%$ \\
\hline Error and no full-text link on target & 1 & $0.5 \%$ & 0 & $0.0 \%$ & 0 & $0.0 \%$ & 0 & $0.0 \%$ \\
\hline Listing of volumes/issues & 0 & $0.0 \%$ & 0 & $0.0 \%$ & 1 & $0.5 \%$ & 0 & $0.0 \%$ \\
\hline Wrong article & 0 & $0.0 \%$ & 0 & $0.0 \%$ & 1 & $0.5 \%$ & 0 & $0.0 \%$ \\
\hline Minor results ${ }^{14}$ & 0 & $0.0 \%$ & 0 & $0.0 \%$ & 0 & $0.0 \%$ & 0 & $0.0 \%$ \\
\hline
\end{tabular}

Table 4. Results with Direct Linking

For 360 Link with 1-Click, the results that did not lead to full text were more varied (see table 5). The top reasons for failure included the link leading to an error indicating the article was not available even though full text for the article was available on the site, the link leading to a list of search results and the link leading to the table of contents for the journal issue or book. In the last case, most of those results were book chapters where 360 Link only generated a link to the main page for the book instead of a link to the chapter. 


\begin{tabular}{|c|c|c|c|c|c|c|c|c|}
\hline & \multicolumn{2}{|c|}{$\begin{array}{l}\text { Sample } 1 \\
\text { Nov. } 2012 \\
n=77\end{array}$} & \multicolumn{2}{|c|}{$\begin{array}{l}\text { Sample } 2 \\
\text { Dec. } 2012 \\
n=70\end{array}$} & \multicolumn{2}{|c|}{$\begin{array}{l}\text { Sample } 3 \\
\text { Jan. } 2013 \\
n=98\end{array}$} & \multicolumn{2}{|c|}{$\begin{array}{l}\text { Sample } 4 \\
\text { Jan. } 2013 \\
n=87\end{array}$} \\
\hline Full Text/Page with full-text link & 45 & $58.4 \%$ & 47 & $67.1 \%$ & 64 & $65.3 \%$ & 55 & $63.2 \%$ \\
\hline Table of Contents & 12 & $15.6 \%$ & 6 & $8.6 \%$ & 10 & $10.2 \%$ & 6 & $6.9 \%$ \\
\hline Error but full text available & 6 & $7.8 \%$ & 11 & $15.7 \%$ & 10 & $10.2 \%$ & 18 & $20.7 \%$ \\
\hline Results list & 6 & $7.8 \%$ & 2 & $2.9 \%$ & 10 & $10.2 \%$ & 4 & $4.6 \%$ \\
\hline Error and no full-text link on target & 6 & $7.8 \%$ & 1 & $1.4 \%$ & 2 & $2.0 \%$ & 2 & $2.3 \%$ \\
\hline Wrong article & 1 & $1.3 \%$ & 1 & $1.4 \%$ & 1 & $1.0 \%$ & 2 & $2.3 \%$ \\
\hline Other & 1 & $1.3 \%$ & 0 & $0.0 \%$ & 0 & $0.0 \%$ & 0 & $0.0 \%$ \\
\hline Abstract/Citation Only & 0 & $0.0 \%$ & 0 & $0.0 \%$ & 1 & $1.0 \%$ & 0 & $0.0 \%$ \\
\hline $\begin{array}{l}\text { Unable to access full text through available } \\
\text { full-text link }\end{array}$ & 0 & $0.0 \%$ & 1 & $1.4 \%$ & 0 & $0.0 \%$ & 0 & $0.0 \%$ \\
\hline Search box & 0 & $0.0 \%$ & 1 & $1.4 \%$ & 0 & $0.0 \%$ & 0 & $0.0 \%$ \\
\hline Minor results 15 & 0 & $0.0 \%$ & 0 & $0.0 \%$ & 0 & $0.0 \%$ & 0 & $0.0 \%$ \\
\hline
\end{tabular}

Table 5. Results with 360 Link: Citations using 1-Click

\section{Link Analysis for all 360 Link Clicks}

Unlike the above tables, which show the results on a citation basis, the table below shows the results for all links produced by 360 Link (see table 6). This includes the following:

1. links used for 1-Click.

2. links in the 360 Link menu that were not used for 1-Click when 360 Link attempted to link to full text using 1-Click

3. links in the 360 Link menu where clicking the link in Summon led directly to the 360 Link menu instead of using 1 -Click 


\begin{tabular}{|c|c|c|c|c|c|c|c|c|}
\hline \multirow[b]{2}{*}{ Full Text/Page with full-text link } & \multicolumn{2}{|c|}{$\begin{array}{l}\text { Sample } 1 \\
\text { Nov. } 2012 \\
n=167\end{array}$} & \multicolumn{2}{|c|}{$\begin{array}{l}\text { Sample } 2 \\
\text { Dec. } 2012 \\
n=158\end{array}$} & \multicolumn{2}{|c|}{$\begin{array}{l}\text { Sample } 3 \\
\text { Jan. } 2013 \\
n=184\end{array}$} & \multicolumn{2}{|c|}{$\begin{array}{l}\text { Sample } 4 \\
\text { Jan. } 2013 \\
n=172\end{array}$} \\
\hline & 81 & $48.5 \%$ & 84 & $53.2 \%$ & 103 & $56.0 \%$ & 87 & $50.6 \%$ \\
\hline Abstract/Citation Only & 0 & $0.0 \%$ & 0 & $0.0 \%$ & 1 & $0.5 \%$ & 0 & $0.0 \%$ \\
\hline $\begin{array}{l}\text { Unable to access full text through available } \\
\text { full-text link }\end{array}$ & 0 & $0.0 \%$ & 1 & $0.6 \%$ & 0 & $0.0 \%$ & 1 & $0.6 \%$ \\
\hline Error but full text available & 9 & $5.4 \%$ & 14 & $8.9 \%$ & 17 & $9.2 \%$ & 23 & $13.4 \%$ \\
\hline $\begin{array}{l}\text { Error and full text not accessible through } \\
\text { full-text link on target }\end{array}$ & 1 & $0.6 \%$ & 0 & $0.0 \%$ & 0 & $0.0 \%$ & 0 & $0.0 \%$ \\
\hline Error and no full-text link on target & 10 & $6.0 \%$ & 1 & $0.6 \%$ & 6 & $3.3 \%$ & 5 & $2.9 \%$ \\
\hline $\begin{array}{l}\text { Failed to find DOI through link in } 360 \text { Link } \\
\text { menu }\end{array}$ & 3 & $1.8 \%$ & 5 & $3.2 \%$ & 5 & $2.7 \%$ & 8 & $4.7 \%$ \\
\hline Main journal page & 22 & $13.2 \%$ & 24 & $15.2 \%$ & 17 & $9.2 \%$ & 15 & $8.7 \%$ \\
\hline Other & 2 & $1.2 \%$ & 0 & $0.0 \%$ & 1 & $0.5 \%$ & 2 & $1.2 \%$ \\
\hline 360 Link menu with no full-text links & 0 & $0.0 \%$ & 2 & $1.3 \%$ & 3 & $1.6 \%$ & 3 & $1.7 \%$ \\
\hline Results list & 9 & $5.4 \%$ & 4 & $2.5 \%$ & 10 & $5.4 \%$ & 3 & $1.7 \%$ \\
\hline Search box & 6 & $3.6 \%$ & 7 & $4.4 \%$ & 5 & $2.7 \%$ & 8 & $4.7 \%$ \\
\hline Table of Contents & 12 & $7.2 \%$ & 6 & $3.8 \%$ & 10 & $5.4 \%$ & 9 & $5.2 \%$ \\
\hline Listing of volumes/issues & 9 & $5.4 \%$ & 9 & $5.7 \%$ & 5 & $2.7 \%$ & 6 & $3.5 \%$ \\
\hline Wrong article & 3 & $1.8 \%$ & 1 & $0.6 \%$ & 1 & $0.5 \%$ & 2 & $1.2 \%$ \\
\hline
\end{tabular}

Table 6. Results with 360 Link: All Links Produced by 360 Link

In addition to recording what happened, we attempted to determine why links failed to reach full text. Even though Direct Linking is very effective, it is not $100 \%$ effective in linking to full text. When excluding records that indicated that only the citation, not full text, would be available through Summon, most of the problems were due to incorrect information in Summon (see table 7). Either the link produced by Summon was incorrectly leading to an error or an abstract when 
full text was available on the target site or Summon incorrectly indicated access to full text was available.

\begin{tabular}{|c|c|c|c|c|c|c|c|c|}
\hline & \multicolumn{2}{|c|}{$\begin{array}{l}\text { Sample } 1 \\
\text { Nov. } 2012 \\
n=8\end{array}$} & \multicolumn{2}{|c|}{$\begin{array}{l}\text { Sample } 2 \\
\text { Dec. } 2012 \\
n=6\end{array}$} & \multicolumn{2}{|c|}{$\begin{array}{l}\text { Sample } 3 \\
\text { Jan. } 2013 \\
n=11\end{array}$} & \multicolumn{2}{|c|}{$\begin{array}{l}\text { Sample } 4 \\
\text { Jan. } 2013 \\
n=5\end{array}$} \\
\hline Citation-Only record in Summon & 1 & $12.5 \%$ & 3 & $50.0 \%$ & 4 & $36.4 \%$ & 1 & $20.0 \%$ \\
\hline Incomplete target collection & 1 & $12.5 \%$ & 0 & $0.0 \%$ & 1 & $9.1 \%$ & 1 & $20.0 \%$ \\
\hline Incorrect coverage in knowledgebase & 0 & $0.0 \%$ & 0 & $0.0 \%$ & 2 & $18.2 \%$ & 0 & $0.0 \%$ \\
\hline Summon has incorrect link & 3 & $37.5 \%$ & 1 & $16.7 \%$ & 2 & $18.2 \%$ & 2 & $40.0 \%$ \\
\hline $\begin{array}{l}\text { Summon incorrectly indicating available access } \\
\text { to full text }\end{array}$ & 3 & $37.5 \%$ & 2 & $33.3 \%$ & 2 & $18.2 \%$ & 1 & $20.0 \%$ \\
\hline
\end{tabular}

Table 7. Reasons for Linking Failure to Link to Full Text through Direct Linking

Table 8 shows the reasons links generated by 360 Link and used for 1-Click did not lead to full text. Most of the failures were caused by three general problems:

1. incorrect metadata in Summon

2. incorrect syntax in the article/chapter link generated by 360 Link

3. target site does not support linking to the article/chapter level 


\begin{tabular}{|c|c|c|c|c|c|c|c|c|}
\hline \multirow[b]{2}{*}{ Incorrect metadata in the Summon OpenURL } & \multicolumn{2}{|c|}{$\begin{array}{l}\text { Sample } 1 \\
\text { Nov. } 2012 \\
n=32\end{array}$} & \multicolumn{2}{|c|}{$\begin{array}{l}\text { Sample } 2 \\
\text { Dec. } 2012 \\
n=23\end{array}$} & \multicolumn{2}{|c|}{$\begin{array}{l}\text { Sample } 3 \\
\text { Jan. } 2013 \\
n=34\end{array}$} & \multicolumn{2}{|c|}{$\begin{array}{l}\text { Sample } 4 \\
\text { Jan. } 2013 \\
n=32\end{array}$} \\
\hline & 2 & $6.3 \%$ & 4 & $17.4 \%$ & 3 & $8.8 \%$ & 4 & $12.5 \%$ \\
\hline $\begin{array}{l}\text { Incomplete metadata in the Summon } \\
\text { OpenURL }\end{array}$ & 0 & $0.0 \%$ & 2 & $8.7 \%$ & 0 & $0.0 \%$ & 0 & $0.0 \%$ \\
\hline $\begin{array}{l}\text { Difference in metadata between Summon and } \\
\text { the target }\end{array}$ & 1 & $3.1 \%$ & 5 & $21.7 \%$ & 0 & $0.0 \%$ & 2 & $6.3 \%$ \\
\hline Inaccurate data in knowledgebase & 0 & $0.0 \%$ & 0 & $0.0 \%$ & 0 & $0.0 \%$ & 1 & $3.1 \%$ \\
\hline Incorrect coverage in knowledgebase & 0 & $0.0 \%$ & 0 & $4.3 \%$ & 0 & $0.0 \%$ & 0 & $0.0 \%$ \\
\hline Link resolver insufficiency & 2 & $6.3 \%$ & 0 & $0.0 \%$ & 1 & $2.9 \%$ & 0 & $0.0 \%$ \\
\hline $\begin{array}{l}\text { Incorrect syntax in the article/chapter link } \\
\text { generated by } 360 \text { Link }\end{array}$ & 6 & $18.8 \%$ & 3 & $13.0 \%$ & 10 & $29.4 \%$ & 7 & $21.9 \%$ \\
\hline $\begin{array}{l}\text { Target site does not support linking to } \\
\text { article/chapter level }\end{array}$ & 11 & $34.3 \%$ & 4 & $17.4 \%$ & 5 & $14.7 \%$ & 6 & $18.8 \%$ \\
\hline Article not individually indexed & 0 & $0.0 \%$ & 1 & $4.3 \%$ & 3 & $8.8 \%$ & 5 & $15.6 \%$ \\
\hline Target error in targetURL translation & 0 & $0.0 \%$ & 0 & $0.0 \%$ & 5 & $14.7 \%$ & 3 & $9.4 \%$ \\
\hline Incomplete target collection & 8 & $25.0 \%$ & 1 & $4.3 \%$ & 1 & $2.9 \%$ & 3 & $9.4 \%$ \\
\hline Incorrect metadata on the target site & 0 & $0.0 \%$ & 1 & $4.3 \%$ & 0 & $0.0 \%$ & 1 & $3.1 \%$ \\
\hline Citation-Only record in Summon & 0 & $0.0 \%$ & 0 & $0.0 \%$ & 0 & $0.0 \%$ & 0 & $0.0 \%$ \\
\hline Cookie & 2 & $6.3 \%$ & 0 & $0.0 \%$ & 0 & $0.0 \%$ & 0 & $0.0 \%$ \\
\hline Item does not appear to have a DOI & 0 & $0.0 \%$ & 0 & $0.0 \%$ & 0 & $0.0 \%$ & 0 & $0.0 \%$ \\
\hline Miscellaneous & 0 & $0.0 \%$ & 0 & $0.0 \%$ & 4 & $0.0 \%$ & 0 & $0.0 \%$ \\
\hline Unknown & 0 & $0.0 \%$ & 1 & $4.3 \%$ & 2 & $5.9 \%$ & 0 & $0.0 \%$ \\
\hline
\end{tabular}

Table 8. Reasons for Linking Failure to Link to Full Text through 1-Click 
Broadening our view of 360 Link to include all links generated by 360 Link during the testing, not only the ones used by 1-Click (see table 9), we see more causes of failure than with 1-Click. Most of the failures were caused by five general problems:

1. Incorrect metadata in Summon.

2. Link resolver insufficiency. We mostly used this classification when 360 Link only provided links to the main journal page or database page instead of links to the article and we thought it might have been possible to generate a link to the article. Sometimes this was due to configuration changes that we could have made and sometimes it was because 360 Link would only create article links if particular metadata was available even if other sufficient identifying metadata was available.

3. Incorrect syntax in the article/chapter link generated by 360 Link.

4. Target site does not support linking to the article/chapter level.

5. Miscellaneous. Most of the links that fell in this category were ones that were intended to go the main journal page by design. These were for journals that are not in vendor-specific packages in the knowledgebase but in large general packages with many journals on different platforms. Because there is no common linking syntax, article-level linking is not possible. This includes packages containing open source titles such as Directory of Open Access Journals (DOAJ) and packages of subscription titles that are not listed in vendorspecific packages in the knowledgebase. 


\begin{tabular}{|c|c|c|c|c|c|c|c|c|}
\hline \multirow[b]{2}{*}{ Incorrect metadata in the Summon OpenURL } & \multicolumn{2}{|c|}{$\begin{array}{l}\text { Sample } 1 \\
\text { Nov. } 2012 \\
n=86\end{array}$} & \multicolumn{2}{|c|}{$\begin{array}{l}\text { Sample } 2 \\
\text { Dec. } 2012 \\
n=74\end{array}$} & \multicolumn{2}{|c|}{$\begin{array}{l}\text { Sample } 3 \\
\text { Jan. } 2013 \\
n=81\end{array}$} & \multicolumn{2}{|c|}{$\begin{array}{l}\text { Sample } 4 \\
\text { Jan. } 2013 \\
n=89\end{array}$} \\
\hline & 9 & $10.5 \%$ & 5 & $6.8 \%$ & 4 & $4.9 \%$ & 8 & $9.0 \%$ \\
\hline $\begin{array}{l}\text { Incomplete metadata in the Summon } \\
\text { OpenURL }\end{array}$ & 0 & $0.0 \%$ & 2 & $2.7 \%$ & 1 & $1.2 \%$ & 3 & $3.4 \%$ \\
\hline $\begin{array}{l}\text { Difference in metadata between Summon and } \\
\text { the target }\end{array}$ & 1 & $1.2 \%$ & 6 & $8.1 \%$ & 2 & $2.5 \%$ & 2 & $2.2 \%$ \\
\hline Inaccurate data in knowledgebase & 0 & $0.0 \%$ & 0 & $0.0 \%$ & 1 & $1.2 \%$ & 5 & $5.6 \%$ \\
\hline Incorrect coverage in knowledgebase & 3 & $3.5 \%$ & 1 & $1.4 \%$ & 2 & $2.5 \%$ & 1 & $1.1 \%$ \\
\hline Link resolver insufficiency & 20 & $23.3 \%$ & 15 & $20.3 \%$ & 9 & $11.1 \%$ & 8 & $9.0 \%$ \\
\hline $\begin{array}{l}\text { Incorrect syntax in the article/chapter link } \\
\text { generated by } 360 \text { Link }\end{array}$ & 7 & $8.1 \%$ & 3 & $4.1 \%$ & 10 & $12.3 \%$ & 11 & $12.4 \%$ \\
\hline $\begin{array}{l}\text { Target site does not support linking to } \\
\text { article/chapter level }\end{array}$ & 17 & $19.8 \%$ & 6 & $8.1 \%$ & 9 & $11.1 \%$ & 10 & $11.2 \%$ \\
\hline Article not individually indexed & 0 & $0.0 \%$ & 1 & $1.4 \%$ & 3 & $3.7 \%$ & 5 & $5.6 \%$ \\
\hline Target error in targeturl translation & 1 & $1.2 \%$ & 3 & $4.1 \%$ & 7 & $8.6 \%$ & 3 & $3.4 \%$ \\
\hline Incomplete target collection & 11 & $12.8 \%$ & 2 & $2.7 \%$ & 5 & $6.2 \%$ & 5 & $5.6 \%$ \\
\hline Incorrect metadata on the target site & 0 & $0.0 \%$ & 1 & $1.4 \%$ & 0 & $0.0 \%$ & 1 & $1.1 \%$ \\
\hline Citation-Only record in Summon & 0 & $0.0 \%$ & 2 & $2.7 \%$ & 3 & $3.7 \%$ & 3 & $3.4 \%$ \\
\hline Cookie & 2 & $2.3 \%$ & 0 & $0.0 \%$ & 0 & $0.0 \%$ & 0 & $0.0 \%$ \\
\hline Item does not appear to have a DOI & 2 & $2.3 \%$ & 4 & $5.4 \%$ & 5 & $6.2 \%$ & 7 & $7.9 \%$ \\
\hline Miscellaneous & 13 & $15.1 \%$ & 22 & $29.7 \%$ & 18 & $22.2 \%$ & 17 & $19.1 \%$ \\
\hline Unknown & 0 & $0.0 \%$ & 1 & $1.4 \%$ & 2 & $2.5 \%$ & 0 & $0.0 \%$ \\
\hline
\end{tabular}

Table 9. Reasons for Linking Failure to Link to Full Text for all 360 Link Links 


\section{Comparison of User Reports and Random Samples}

When we look at user-reported problems during the same period over which we conducted our manual process (November 1, 2012-January 29, 2013), we see that users reported a problem roughly $0.2 \%$ of the time $(0.187 \%$ of searches resulted in a problem report while $0.228 \%$ of fulltext clicks resulted in a problem report). See table 10.

\begin{tabular}{|l|l|l|l|l|l|}
\hline Sample Period & $\begin{array}{l}\text { Problems } \\
\text { Reported }\end{array}$ & $\begin{array}{l}\text { ArticlesPlus } \\
\text { Searches }\end{array}$ & $\begin{array}{l}\text { MGet It } \\
\text { Clicks }\end{array}$ & $\begin{array}{l}\text { Problems } \\
\text { Reported per } \\
\text { Search }\end{array}$ & $\begin{array}{l}\text { Problems } \\
\text { Reported per } \\
\text { MGet It Click }\end{array}$ \\
\hline $\begin{array}{l}11 / 1 / 2012- \\
11 / 30 / 2012\end{array}$ & 225 & 111,062 & 95,218 & $0.203 \%$ & $0.236 \%$ \\
\hline $\begin{array}{l}12 / 1 / 2012- \\
12 / 31 / 2012\end{array}$ & 105 & 74,848 & 58,346 & $0.140 \%$ & $0.180 \%$ \\
\hline $\begin{array}{l}1 / 1 / 2013- \\
1 / 29 / 2013\end{array}$ & 100 & 44,204 & 34,692 & $0.226 \%$ & $0.288 \%$ \\
\hline & 430 & 230,114 & 188,256 & $0.187 \%$ & $0.228 \%$ \\
\hline
\end{tabular}

Table 10. User Problem Reports During the Sample Period

The number of user-reported errors is significantly less than what we found through our systematic sampling (see table 2). Where the error rate based on user reports would be roughly $0.2 \%$, the more systematic approach showed a $20 \%$ error rate. Relying solely on user reports of errors to judge the reliability of full-text links dramatically underreports true problems by a factor of 100 .

\section{CONCLUSIONS AND NEXT STEPS}

Comparison of user reports to random sample testing indicates a significant underreporting of problems on the part of users. While we have not conducted similar studies across other vendor databases, we suspect that user-generated reports likewise significantly lag behind true errors. Future research in this area is recommended.

The number of problems discovered in full-text items that are linked via an OpenURL is discouraging; however, the ability of the Summon Discovery Service to provide accurate access to full text is an overall positive because of its direct link functionality. More than 95\% of directlinked articles in our research led to the correct resource (table 3). One-click (OpenURL) resolution was noticeably poorer, with about $60 \%$ of requests leading directly to the correct fulltext item. More alarming, we found that, of full-text requests linked through an OpenURL, a large 
portion-20\%-fail. The direct links (the result of publisher-discovery service negotiations) are much more effective. This discourages us from feeling any complacency about the effectiveness of our OpenURL link resolution tools. The effort spent maintaining our link resolution knowledge base does not make a long-term difference in the link resolution quality.

Based on the data we have collected, it would appear that more work needs to be done if OpenURL is to continue as a working standard. While our data shows that direct linking offers improved service for the user as an immediate reward, we do feel some concern about the longer-term effect of closed and proprietary access paths on the broader scholarly environment. From the library's perspective, the trend to direct linking creates the risk of vendor lock-in because the vendorcreated direct links will not work after the library's business relationship with the vendor ends. An OpenURL is less tightly bound to the vendor that provided it. This lock-in increases the cost of changing vendors. The emergence of direct links is a two-edged sword: users gain reliability but libraries lose flexibility and the ability to adapt.

The impetus for improving OpenURL linking must come from libraries because vendors do not have a strong incentive to take the lead in this effort, especially when it interferes with their competitive advantage. We recommend that libraries collaborate more actively on identifying patterns of failure in OpenURL link resolution and remedies for those issues so that OpenURL continues as a viable and open method for full-text access. With more data on the failure modes for OpenURL transactions, libraries and content providers may be able to implement systematic improvements in standardized linking performance. We hope that the methods and data we have presented form a helpful beginning step in this activity.

\section{ACKNOWLEDGEMENT}

The authors thank Kat Hagedorn and Heather Shoecraft for their comments on a draft of this manuscript.

\section{REFERENCES}

1. NISO/UKSG KBART Working Group, KBART: Knowledge Bases and Related Tools, January 2010, http://www.uksg.org/sites/uksg.org/files/KBART_Phase_I_Recommended_Practice.pdf.

2. National Information Standards Organization (NISO), "ANSI/NISO Z39.88 - The OpenURL Framework for Context-Sensitive Services," May 13, 2010, http://www.niso.org/kst/reports/standards?step=2\&project_key=d5320409c5160be4697dc 046613f71b9a773cd9e.

3. Adam Chandler, Glen Wiley, and Jim LeBlanc, "Towards Transparent and Scalable OpenURL Quality Metrics," D-Lib Magazine 17, no. 3/4 (March 2011), http://dx.doi.org/10.1045/march2011-chandler. 
4. Ibid.

5. National Information Standards Organization (NISO), Improving OpenURLs through Analytics (IOTA): Recommendations for Link Resolver Providers, April 26, 2013, http://www.niso.org/apps/group_public/download.php/10811/RP-21-2013_IOTA.pdf.

6. NISO/UKSG KBART Working Group, KBART: Knowledge Bases and Related Tools.

7. Oliver Pesch, "Improving OpenURL Linking," Serials Librarian 63, no. 2 (2012): 135-45, http://dx.doi.org/10.1080/0361526X.2012.689465.

8 Jason Price and Cindi Trainor, "Chapter 3: Digging into the Data: Exposing the Causes of Resolver Failure,” Library Technology Reports 46, no. 7 (October 2010): 15-26.

9. Ibid., 26.

10. Xiaotian Chen, "Broken-Link Reports from SFX Users," Serials Review 38, no. 4 (December 2012): 222-27, http://dx.doi.org/10.1016/j.serrev.2012.09.002.

11. Lois O’Neill, “Scaffolding OpenURL Results,” Reference Services Quarterly 14, no. 1-2 (2009): 13-35, http://dx.doi.org/10.1080/10875300902961940.

12. http://www.lib.umich.edu/. See the ArticlesPlus tab of the search box.

13. One problem we had in testing was that log data for February 2013 was not preserved. This would have been used to build the sample tested in April 2013. To get around this we decided to take two samples from the January 2013 log.

14. The "Minor results" row is a combination of all results that did not represent at least $0.5 \%$ of the records using Direct Linking for at least one sample. This includes the following results: Error but full text available, Error and full text not accessible through full text link on target, Main journal page, 360 Link menu with no full text links, Results list, Search box, Table of Contents, and Other.

15. The "Minor results" row is a combination of all results that did not represent at least $0.5 \%$ of the records using 360 Link for at least one sample. This includes the following results: Error and full text not accessible through full text link on target, Main journal page, 360 Link menu with no full text links, Listing of volumes/issues. 